\title{
Modelling of cutting block cut surface at faceted surfaces machining using planetary gear set
}

\author{
Vadim Kuts ${ }^{1, *}$, Mikhail Razumov ${ }^{1}$, and Nikolay Kalutskikh ${ }^{1}$ \\ ${ }^{1}$ Federal State Budgetary Educational Institution of Higher Education "Southwest State University", SWSU International Office, 94, 50 \\ let Oktyabrya, Kursk, Russia
}

\begin{abstract}
The article resolved the relevant problem to assign process parameters for polygonal turning machining ensuring the component has its pre-set characteristics. To accomplish this, the authors modelled the machining process and described the cut surface formed by the cutter block edge during machining.
\end{abstract}

Today cylindrical components with multi-faceted surfaces have found application in various areas of the economy, in particular: machine construction, instrument engineering, robotics, agriculture, mining and even the medical industry [1].

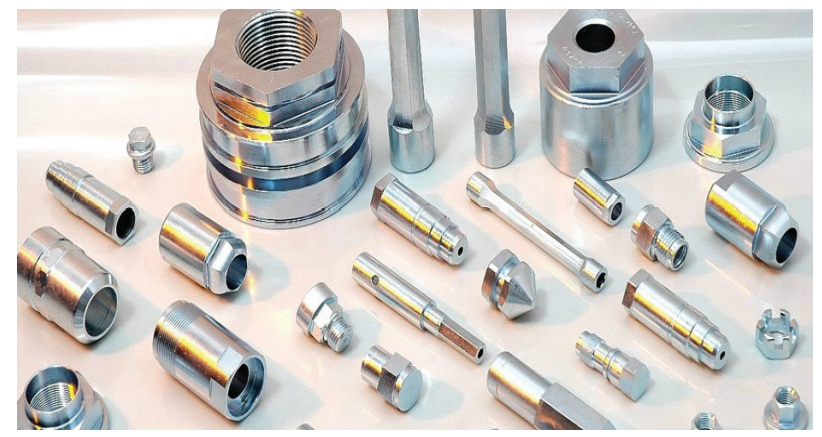

Fig 1. Examples of details with polyhedral surfaces

The conducted analysis of the production methods for faceted surfaces helped to choose the planetary motion method of the turning machine cutting edges. This method works as follows: the planetary gear set assigns a complex curve trajectory (trochoid) to the cutting tool point Fig.1 [1].

To determine the planetary gear set structural parameters, the authors resolved the problem of the rectangle side approximation error calculation with the prolonged trochoid section [1]. However, to assign the machining process parameters the component has its preset characteristics, it is necessary to model the machining process, namely, to make a cut surface model.

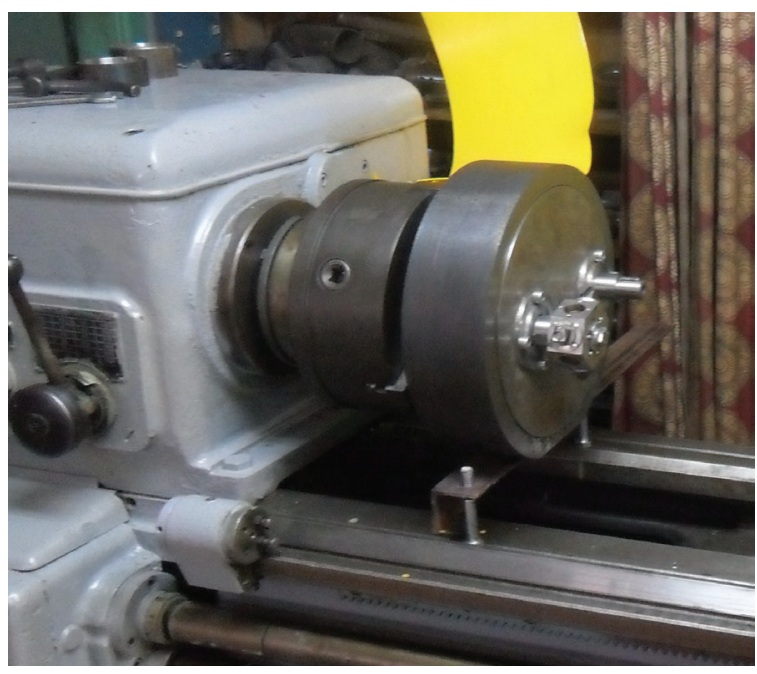

Fig. 2. Planetary Gear Set

Generally, the cut surface is described by the formula $Q_{i}(\varphi(t), \theta(t) z(t), S)=={ }^{6} A(\varphi(t))^{2} A(R-r) \cdot{ }^{6} A(-\theta(t)) \cdot r_{u i}(S)(1)$

Where

$\varphi(t)=\frac{\pi n}{30} \cdot t ; \theta(t)=\frac{R}{r} \cdot \frac{\pi n}{30} \cdot t ; z(t)=\frac{S_{\text {мин }}}{60} \cdot t, S_{\text {мин }}-$ feed per minute, $N$ - number of the cutting block rotations in relation to the workpiece.

Let us build a model for cutting block edges. Fig. 3 presents a square indexable insert.

* Corresponding author: kuc-vadim@yandex.ru 


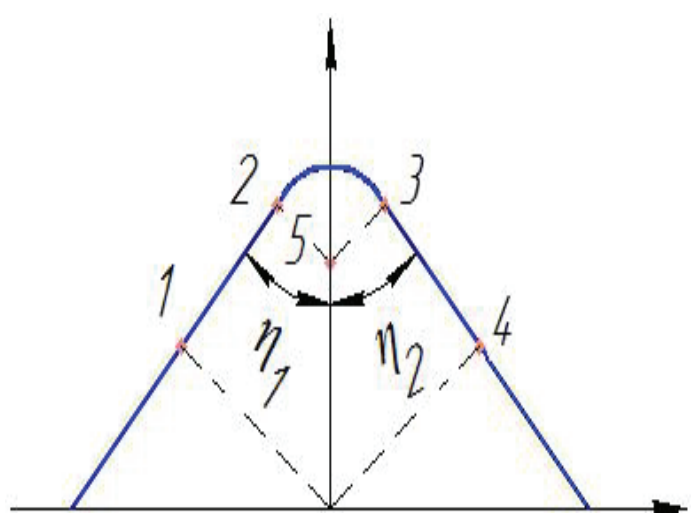

Fig. 3. Design model for the indexable insert cutting edge points: 1,2,3,3 5 - reference points; $\eta 1 \eta 2$ - angles between the $\mathrm{X}$ axis and the insert surface

Let us determine the generating points coordinates Point 1 coordinates:

$$
x_{1}=0,5 d \cdot \sin \eta_{1} ; y_{1}=0,5 d \cdot \sin \eta_{1}
$$

Point 2 coordinates:

$$
x_{2}=\frac{\sqrt{2}}{2} d \cdot \cos \eta_{1} ; y_{2}=-r \cdot \sin \eta_{1}
$$

Point 3 coordinates:

$$
x_{3}=x_{2} ; y_{2}=-y_{2}
$$

Point 4 coordinates:

$$
x_{4}=x_{1} ; y_{4}=-y_{1}
$$

Point 5 coordinates:

$$
\begin{gathered}
x_{5}=\frac{\sqrt{2}}{2} d-r \cdot \sqrt{2} ; y_{5}=0 \\
r_{\Pi}=[x(S), y(S), z(S), 1]^{T}
\end{gathered}
$$

where

$$
\begin{aligned}
& y(S)=\left\{\begin{array}{l}
y_{1} ; S \leq 0 \\
y_{1}+S ; 0<S \leq y_{4}-y_{1} \\
y_{u} ; S>y_{u}-y_{1}
\end{array}\right. \\
& x(S)=\left\{\begin{array}{l}
x_{1} ; S \leq 0 \\
\left(x_{2}-x_{1}\right) \cdot\left(y(S)-y_{1}\right) /\left(y_{2}-y_{1}\right)+x_{1} ; 0<S \leq y_{2}-y_{1} \\
x_{5}+\sqrt{r^{2}-\left(y(S)-y_{5}\right)^{2}} ; y_{2}-y<S \leq y_{3}-y_{1} \\
\left(x_{4}-x_{3}\right) \cdot\left(y(S)-y_{3}\right) /\left(y_{4}-y_{3}\right)+x_{3} ; y_{3}-y_{1}<S \leq y_{4} \\
x_{4} ; S<y_{4}
\end{array}\right. \\
& N_{\Pi}(S)=\left[-\bar{j} \cdot \bar{r}_{s}(S) \cdot \sin \gamma_{\Pi} ; \bar{i} \cdot \bar{r}_{s}(S) \cdot \sin \gamma_{\Pi} ;-\cos \gamma_{\Pi} ; 0\right]^{T} \\
& N_{3}(S)=\left[-\bar{j} \cdot \bar{r}_{s}(S) \cdot \cos \alpha_{\Pi} ; \bar{i} \cdot \bar{r}_{s}(S) \cdot \cos \alpha_{\Pi} ; \sin \alpha_{\Pi} ; 0\right]^{T}
\end{aligned}
$$

Further, let us set the indexable insert parameters; the transition to the coordinates system 1 is the first action

$$
{ }^{01} A={ }^{2} A(-d) \cdot{ }^{6} A\left(\frac{\pi}{2}\right) \cdot{ }^{5} A\left(-\frac{\pi}{2}\right)
$$

Rotation for the angle $\lambda$ is the second action

$$
{ }^{12} A={ }^{6} A(-\lambda)
$$

After that, let us set the insert for the angle

$$
\begin{aligned}
& \gamma_{g}=\gamma_{K}-\gamma_{\Pi K} \\
& { }^{23} A={ }^{4} A\left(-\gamma_{g}\right)
\end{aligned}
$$

Move to the rotation center

$$
{ }^{34} A={ }^{2} A\left(-S_{I}\right) \cdot{ }^{3} A\left(-r_{I I}\right)
$$

If $\varphi \neq \varphi_{2}$, set the angle $\varphi$

$$
\begin{gathered}
{ }^{45} A={ }^{5} A(\varphi) \\
{ }^{56} A={ }^{6} A(-(0,5 d+m-r)) \\
{ }^{67} A={ }^{6} A\left(\frac{\pi}{2}\right) \cdot{ }^{2} A\left(-\frac{\pi}{2}\right)
\end{gathered}
$$

The setting matrix calculation in the coordinates system

Reference data:

$\bar{j}_{21}$ - vector $\bar{j}_{2}=[0,1,0,0]^{T}$ presented in the coordinates system $x_{1}, y_{1}, z_{1}$

$\bar{k}_{21}$ - vector $\bar{k}_{2}=[0,0,1,0]^{T}$ presented in the coordinates system $x_{1}, y_{1}, z_{1}$

$\bar{r}_{21}$ - vector defining the position of the coordinates $x_{2}, y_{2}, z_{2}$ origin within the system $x_{1}, y_{1}, z_{1}$

The $A_{21}$ matrix elements are determined by the system

$$
\left\{\begin{array}{l}
\bar{j}_{21}=A_{21} \cdot \bar{j}_{2} \\
\bar{k}_{21}=A_{21} \cdot \bar{k}_{2} \\
{\left[\bar{j}_{21} \times \overline{k_{21}}\right]=A_{21} \cdot \bar{i}_{2}} \\
\bar{r}_{21}=A_{21} \cdot e^{4}
\end{array}\right.
$$

where $\bar{i}_{2}=(1,0,0,0)^{T}$

$$
A_{21}=\left[\begin{array}{cccc}
\bar{i}_{1} \cdot\left[\bar{j}_{1} \times \bar{k}_{21}\right] & \bar{i}_{1} \cdot \bar{j}_{21} & \bar{i}_{1} \cdot \bar{k}_{21} & \bar{i}_{1} \cdot \bar{r}_{21} \\
\bar{j}_{1} \cdot\left[\bar{j}_{1} \times \bar{k}_{21}\right] & \bar{j}_{1} \cdot \bar{j}_{21} & \bar{j}_{1} \cdot \bar{k}_{21} & \bar{j}_{1} \cdot \bar{r}_{21} \\
\bar{k}_{1} \cdot\left[\bar{j}_{1} \times \bar{k}_{21}\right] & \bar{k}_{1} \cdot \bar{j}_{21} & \bar{k}_{1} \cdot \bar{k}_{21} & \bar{k}_{1} \cdot \bar{r}_{21} \\
0 & 0 & 0 & 1
\end{array}\right]
$$

The method for calculation of the residual ridges and roughness parameters

1. Define the point on the cutting edge which contacts with the component surface (shape-generating point) by solving the following equation

$$
\bar{j} \cdot \bar{Q}(S, t)=0
$$

In relation to the $\mathrm{S}$ edge parameter at $\mathrm{t}=0$ 
2. Calculate the $A_{W}$ matrix elements for setting the sectional plane coordinates system under the set parameters

$$
[0,0,-1,0]^{T},[-1,0,0,0]^{T}, Q(S, t)
$$

Determine the coordinates for the A point

$$
r_{A}=A_{W} \cdot Q(S, t)
$$

Determine the coordinates for the B point

$$
r_{B}=A_{W} \cdot Q\left(S, t+T_{o \bar{\sigma}}\right)
$$

Determine the coordinates for the $\mathrm{C}$ point by solving the equation system

$$
\left\{\begin{array}{l}
\bar{i}_{w} \cdot \bar{A}_{w} \cdot Q\left(S_{1}, t_{1}\right)=\bar{i}_{w} \cdot \bar{A}_{w} \cdot Q\left(S_{2}, t_{2}\right) \\
\bar{j}_{w} \cdot \bar{A}_{w} \cdot Q\left(S_{1}, t_{1}\right)=\bar{j}_{w} \cdot \bar{A}_{w} \cdot Q\left(S_{2}, t_{2}\right) \\
\bar{k}_{w} \cdot A_{w} Q\left(S_{1}, t_{1}\right)=0 \\
\bar{k}_{w} \cdot A_{w} Q\left(S_{2}, t_{2}\right)=0 \\
0 \leq S_{1} \leq S_{m 4} \\
0 \leq S_{2} \leq S_{m 4} \\
t-\frac{T_{o \sigma}}{4} \leq t_{1} \leq t+\frac{T_{o \sigma}}{4} \\
t+T_{o \sigma}-\frac{T_{o \sigma}}{4} \leq t_{2} \leq t+T_{o \sigma}+\frac{T_{o \sigma}}{4}
\end{array}\right.
$$

In relation to the $S_{1}, S_{2}, t_{1}, t_{2}$. parameter

Hence $r_{c}=A_{W} \cdot Q\left(S_{1}, t_{1}\right)$

Assessment for the layers being cut

1) Define the normal vector towards the cut surface at the cut-in moment $t$

$$
\begin{aligned}
& \bar{N}_{p i}(S, t)=\left[\bar{Q}_{i s} \cdot(S, t) \times \bar{Q}_{i t} \cdot(S, t)\right] \cdot \\
& \operatorname{sign}\left\{\begin{array}{l}
-\left[\bar{Q}_{i s} \cdot(S, t) \times \bar{Q}_{i t} \cdot(S, t)\right] \cdot{ }^{6} A(\varphi(t)) \cdot{ }^{2} \\
A(R-r) \cdot{ }^{6} A(Q(t)) \cdot \bar{N}_{s i}(S)
\end{array}\right\}
\end{aligned}
$$

Let the $A_{j}$ transition matrix be defined in the system of $x_{j}, y_{j}, z_{j}$ coordinates with the origin in the $\bar{Q}_{i}(S, t)$ point and the $y_{j}$ axis along the $\bar{Q}_{i s}(S, t)$ vector and the $z_{j}$ axis along the $\bar{N}_{p i}(S, t)$ vector

Define the cross point of the $z_{j}$ axis with the cut surface of the i cutter shaped during the previous cutting block rotation

$$
\left\{\begin{array}{l}
\bar{i}_{j} \cdot \overline{A_{j} \cdot Q_{i}\left(S^{*}, t+\Delta t\right)}=0 \\
\bar{j}_{j} \cdot \overline{A_{j} \cdot Q_{i}\left(S^{*}, t+\Delta t\right)}=0 \\
0 \leq S \leq S_{n} \\
t-T_{o \sigma}-\frac{T_{o \sigma}}{N_{r}}<\Delta t<t-T_{o \sigma}+\frac{T_{o \sigma}}{N_{r}}
\end{array}\right.
$$

The system is solved in relation to the $S^{*}$ and $\Delta t$ parameters

Define the thickness $Q_{1}(S, t)$

$$
Q_{1}(S, t)=F_{1}(S, t) \cdot \bar{k}_{i} \cdot \overline{A_{j} \cdot Q_{i}\left(S^{*}, t+\Delta t\right)}
$$

Let the thickness value of the layer being cut limited by the workpiece material be defined as follows:

Solve the equation system in relation to the $U$ and $V$ parameters

$$
\left\{\begin{array}{l}
\bar{i}_{j} \cdot \overline{A_{j} \cdot P R_{z}(U, V)}=0 \\
\bar{j}_{j} \cdot \overline{A_{j} \cdot P R_{z}(U, V)}=0 \\
0 \leq U \leq 2 \pi \\
0 \leq V \leq H_{s a z}
\end{array}\right.
$$

where $H_{\text {за }}$ - workpiece thickness.

2) Calculate the thickness $a_{2}(S, t)$

$$
a_{2}(S, t)=F_{1}(S, t) \cdot \bar{k}_{j} \cdot \overline{A_{j} \cdot Q P R \cdot(U, V)}
$$

The thickness for the layer being cut is calculated as

$$
a(S, t)=\min \left(a_{1}(S, t), a_{2}(S, t)\right)
$$

Basing upon the model built for the cut surface, it is possible to calculate assessment parameters for the multi-faceted surfaces machining with further determining of the rational values for the polygonal turning parameters.

\section{References}

1. M.S. Razumov, Enhancing Performance of Multifaceted Outer Surfaces Shape Generation by means of Planetary Gear Set: the author's abstract of the thesis, Candidate in Engineering Science (Kursk, 2011)

2. M.S. Razumov, A.N Grechukhin., A.O. Gladyshkin, Calculation of the blank twist angle at processing with planetary turning, Proceedings of the Institution of Mechanical Engineers, Part C: Journal of Mechanical Engineering Science, 230 (18), pp. 3298-3303 (2016) $10.1177 / 0954406215608657$

DOI:

3. M.S. Razumov, A.O. Gladyshkin, A.I. Pykhtin, Evaluation of rational quantity of profile momenttransferring joints sides / [Procjena racionalne količine stranica profilnih spojeva za prijenos okretnog momenta], Source of the Document Tehnicki Vjesnik 23 (2), pp. 575-577 (2016) DOI: 10.17559/TV-20140614032348

4. M. Razumov, A. Grechukhin, A. Pykhtin, Determination of Shape Errors during Polygonal Turning of Polyhedrons with an Odd Number of Faces / Procedia Engineering 150, PP 844-848 (2016) DOI: 10.1016/j.proeng.2016.07.130 
5. A.I. Barbot'ko, M.S. Razumov, A.I.Pykhtin, P.A. Ponkratov, Selecting the cutting edge of a shaping tool, Russian Engineering Research 35 (5), pp. 344346 (2015) DOI: 10,3103 / S1068798X15050068

6. M. Razumov, Form error calculation during polygonal sharpening of polyhedrons with even number of sides, Metallurgical and Mining Industry 7 (1), pp. 66-69

7. M.S. Razumov, Technological parameters determination of faced rolls combined treatment / Metallurgical and Mining Industry, 7 (2), pp. 178182 (2015)

8. M.S. Razumov, A.O. Gladyshkin, E.I. Yatsun, A.A. Zinovkin, O.S. Zubkova, Selection of rational geometrical parameters of profile of moment transmitted connections, Metallurgical and Mining Industry 7 (8), pp. 512-516 (2015)

9. M. Razumov, A. Gladyshkin, V. Kassikhin, A. Pykhtin, E. Skripkina, Stress calculation of moment transmitting roll with profile on the base of Reuleaux triangle, Metallurgical and Mining Industry 7 (8), pp. 512-516 (2014)

10. M.S. Razumov, A.I. Pykhtin, A.V. Maslennikov, Error of polyhedral profiles in single-cutter shaping by means of a planetary mechanism, Russian Engineering Research 32 (9-10), pp. 681-684 (2012) DOI 10,3103 / S1068798X12070180

11. A.I. Barbot'ko, A.V. Maslennikov, M.S. Razumov, Attachment for clamping bushes when shaping their polyhedral external surfaces, Russian Engineering Research, 31(12), pp. 1253-12542011 DOI: 10.3103/S1068798X11120069

12. Y.A. Maksimenko, V.V. Kuts, Machining by a disk mill of variable radius, Russian Engineering Research, Volume 34, Issue 12, Pages 785-788 (2014)

13. V.V. Kuts, I.V. Kucheryaev, Machine-tool adjustment in machining the housings of composite mills, Russian Engineering Research, Volume 28, Issue 10, Pages 1007-1009 (2008)

14. V.V. Kuts, The profile distortion value calculation for shaped to be machined surface at the CAD/CAM - development for assembled shaped mills, Avtomatizatsiya i Sovremennye Tekhnologii, Issue 11, Pages 5-7 (2004)

15. S.G. Emel'yanov, V.V. Kuts, M.S. Merzhoeva, Graphoanalytical design method of combined core drills equipped with $r B$ eplaceable and indexing cutting inserts, Avtomatizatsiya i Sovremennye Tekhnologii, Issue 11, Pages 19-23 (2003)

16. Y.A. Maksimenko, V.V. Kuts, Analysis of changes in error processing rk-profile shaft with teeth resharpening cutters with radial constructive feed, Spravochnik. Inzhenernyi zhurnal, pp.008-012 (2014)

17. O. Kuts, A. Gorokhov, A. Prokofiev, Profile simulation of rated workable surface in thin-walled part with small angle of taper and generating surfaces of compound milling cutters, International Conference on Mechanical Engineering, Automation and Control Systems (MEACS), Tomsk, pp. 1-4 (2015) doi: 10.1109/MEACS.2015.7414900

18. L.G. Vainer, A.G. Ivakhnenko, I.V. Karabanov, Systematic Dynamic Factors in the Shaping of Opposite End Surfaces, Russian Engineering Research 5, pp. 340-345 (2014)

19. A.V. Kirichek, A.G. Ivakhnenko, E.O. Ivakhnenko, A.Y. Altukhov, Geometric Accuracy of the Machines with Strut-Type Structures, International Journal of Applied Engineering Research 21, pp. 995-995 (2014)

20. O. Kuts, A. Gorokhov, A. Prokofiev, Assessment of error in position and orientation of replaceable polyhedral plates in disk milling cutters for profile shafts machining, 2015 International Conference on Mechanical Engineering, Automation and Control Systems (MEACS), Tomsk, pp. 1-5 (2015) doi: 10.1109/MEACS.2015.7414899

21. A.I. Timchenko, Tekhnologiya izgotovleniya detaley profil'nykh besshponochnykh soedineniy [Manufacturing technology of keyless connection of profile pieces] (Moscow, VNIITEMR, 1988)

22. S.G. Emel'yanov, A.O. Gladyshkin, M.S. Razumov, S.F. Yatsun, Automatization of work preparation of profile rolls, Izvestiya YuZGU 1(1), 113-116. (2012)

23. A.I. Barbot'ko, M.S. Razumov, Lathing of polyhedrons with even number of sides, Vestnik mashinostroeniya, No1, p. 46-48 (2010)

24. A.I. Barbot'ko, P.A. Ponkratov i M.S. Razumov, Metod generatornoy obrabotki profil'nykh valov dolbyakami [Method of generating processing of grooved rolls by form cutters], V Mezhdunarodnaya nauchno-tekhnicheskaya konferentsiya «Mashinostroenie - osnova tekhnologicheskogo razvitiya Rossii (TM-2013)». Kursk, YuZGU, p.p. 440-442 (2013)

25. V.N. Kassikhin, M.S. Razumov, A.O. Gladyshkin, N.E. Bykovskaya, Automation of durability calculation for shaft torsion, News of Southwest state university, Equipment and technologies, SWSU, No. 2, p. 1, pp. 179-181 (2012)

26. S.G. Emelyanov, M.S. Razumov, S.A. Chevychelov, A.N. Grechukhin, A.O. Gladyshkin, Method of forming profile sections wagons springrailway, Proceedings of the Southwestern State University, Series: Technology 2, 23-28 (2013)

27. A.I. Barbotko, M.S. Razumov, A.O. Gladyshkin, P.A. Ponkratov, O.V. Eskova, O.V Ovchinkin, Automated system for the implementation of graphic solutions power function, Proceedings of the Southwestern State University 1, 90-94 (2013)

28. Barbot'ko A and Gladyshkin A. The basis of theory of mathematical modelling: text-book (St. Oskol: “TNT''Ltd, 2009) 
29. V. Vorona, I. Shchurov, Working kinematic front angle in turning a sinusoidal linear surface, Russian Engineering Research 5, 469-472 (2012)

30. V. Vorona, S. Chinenov, Rational rear cutter angles for multipassturning of a complex sinusoidal contour surface, Russian Engineering Research 11, 1156-1157 (2011)

31. A. Herberg, Modeling of self-induced vibrations that occur during the machining process of casting patterns with the use of the fuzzy neural networks method, Archives of Metallurgy and Materials 3, 871-875 (2013)

32. S. Wiewiorowska, Analysis of the influence of drawing processparameters on the mechanical properties of trip-structure steelwires. Archives of Metallurgy and Materials 2, 573-578 (2013)

33. Z. Muskalski, Selected problems from the highcarbon steel wire drawing theory and technology, Archives of Metallurgy and Materials 2, 527-535 (2014) 